\title{
Reflections on the Doctor-Patient Relationship in Medical Humanities from the Perspective of Care Ethics*
}

\author{
Huei-Ya Chen ${ }^{1}$ Wei-Ding Tsai ${ }^{1{ }^{* *}}$ \\ ${ }^{l}$ National Chengchi University, Taipei, Taiwan \\ ${ }^{* *}$ Corresponding author. Email: sprache@nccu.edu.tw
}

\begin{abstract}
The medical humanities pursue the person-centered relationship as its ideal mode of doctor-patient relationship. Currently its mainstream position is the principle of patient autonomy, which aims to recognize a patient as a subject of rights to be treated fairly in the doctor-patient relationship and medical decision. However, in actual scenes of medical practice, this principle seems to weaken the professionality of medical staff on the one hand and to ignore the helplessness of patients in their painful situation on the other hand. To solve this dilemma, this article attempts to start from Nel Noddings' criticism about Western traditional ethics of justice which regards human beings as abstract subjects and ignores their existential relationship and the fragility of human existence. According to Eva Kittay's theory of dependency relations and Annette Baier's moral theory of trust, both based on Noddings' care ethics, it is clear that medical humanities without the supplement of care ethics can hardly achieve their ideal of a "person-centered" relationship in medicine. Thus, we try to explain how the doctorpatient relationship from care ethics is more suitable for the existential situations of patients and the professional medical staff, and how it can respond to the medical dilemma mentioned above.
\end{abstract}

Keywords: Medical humanities, Doctor-patient relationship, Patient autonomy, Ethics of justice, Care ethics.

\section{INTRODUCTION: A CRITICISM OF CURRENT MEDICAL HUMANITIES}

Nowadays, humanistic reflections on medical behaviors are usually carried out under the interdisciplinary framework of medical humanities. "Medical humanities" is a relatively young subject and has not yet had a well-recognized clear definition. Tracing back its history, the concept of "medical humanities" appeared at first in the United States in 1960s, and gradually caught the major attention in 1990s. It is generally used to refer to certain interdisciplinary issues where humanities, social sciences, and cultural activities are applied to medical education and medical practice. The emphasis on medical humanities is now common in clinical practice and has become one of core

*Fund: This study was funded by the RFBR-MOST joint research project "Philosophy of Being Human as the Core of Interdisciplinary Research" (MOST 109-2923-H-004-001-MY3) curriculums for medical education design.

When trying to define medical humanities, some scholars regard medical humanities as a medical subdiscipline to rebuild the long-neglected relation between medicine and humanities. Meanwhile, others take it as a new interdisciplinary perspective to integrate humanities into medicine. [3] The relationship between those different understandings of medical humanities can be viewed as a tension between the operation of medicine as a natural science and the existence of medicine as a human science. [10] The difference between both sides actually reflects dual aspects of "medicine", and each of them tends to emphasize one aspect. "Medicine" as a techne ( $\left.\varepsilon_{\varepsilon}^{\prime} \chi \vee \eta\right)$ in Ancient Greece means not only a theoretical knowledge of human body, but also an art with a practical knowledge. For example: When a patient comes to a physician, the physician observes her/his symptoms, examines the function of her/his body, and listens to her/his concerns. Although the 
patient can be seen as an objective, physiological organism with a biomedical disease, she/he can also be experienced as a sufferer of an illness. What the patient actually suffers is not a merely biomedical state in her/his body, but an alienation, a fall-out from her/his familiar life-world. [14] It cannot be identical with disease symptoms or medical diagnosis. The sufferer is thus an embodied subject who lives her/his body and rather not only possesses a body as a measurable object. [18] Correspondingly, the physician needs to rely on her/his own professional ability and judgement to diagnose this disease theoretically on the one hand and to treat the patient as a lived body practically on the other hand, in order to make her/his patient fully recover from the illness.

No matter how we understand "medical humanities", they are currently mainly introduced into the formative education of medical personnel. Among them, ethics - including medical ethics, bioethics, clinical ethics and research ethics - is most valued for medical professionals. They hope medical humanities can provide a set of ethical guidelines immediately used by medical personnel for health care and by medical researcher for biological experiments. Behind this pragmatic demand, we find a dilemma of modern medicine. Modern medicine is eager to pursue scientific standards and to promote the scientific method of "evidence-based medicine", in order to be able to regard itself as a branch of natural science. Through this method, modern medicine does construct a powerful system of scientific knowledge about human body and related technical means, but a sacrifice for this achievement is to make the real situation of sufferer as a whole person fall outside physician's most concerns. This leads modern medicine to a separation between theoretical and practical knowledge to a certain degree. Meanwhile, the medical professionals are also aware of the gradual loss of humanity in modern medicine and turn to medical humanities for help to improve the rigid system of modern medical institutions and to prevent medical activities from turning into service industrialization. In view of the crisis of dehumanization, modern medicine tries to regain the human warmth in scientifically therapeutic behaviours through humanistic reflections. As a result, physicians pay more attention on the suffering of patients. Thus, the worry about dehumanization of medical technology and the emphasis on medical humanities make the significance of the "subjective" experience of patients generally acknowledged in modern medicine. In addition to collecting and diagnosing objective clinical data of patients, a humanized process of treatment in clinical practice needs to include the care for the well-being of patients as its core value.

The humanization of medicine through medical humanities is aimed at achieving the so-called "patient-centered medicine". [7] At first sight, the concept of patient-centeredness can be traced back to the following statement in Hippocratic Oath: "I will apply dietetic measures for the benefit of the sick according to my ability and judgment; I will keep them from harm and injustice". This ancient ethical statement established a primary focus on the well-being of patients under a patient-centered consideration and later in the $20^{\text {th }}$ century developed by moral philosophers into four principles which constitute the basis of modern biomedical ethics: autonomy, nonmaleficence, beneficence, and justice. Furthermore, Tristram Engelhardt, an American medical philosopher, argues in The Foundations of Bioethics that "autonomy" is the necessary condition of ethics. [17] Accordingly, "patient autonomy" becomes one of the most concerned topics in current medical humanities. It becomes also the main guiding norm in today's medical practice scene and is normally reflected in the declaration of patient rights announced in medical institutions. If we look closely at such a declaration, we can find out its theoretical presupposition clearly that both physicians and patients are independent individuals, enter the clinical relationship voluntarily and have to respect each other during in this relationship i.e., the doctor is required to respect the patient's decision and the patient doctor's profession. It seems that modern medicine has found here a way out of the dehumanization of medical technology. For many medical philosophers, modern medicine is now, due to the respect for the patient as an autonomous subject, able to consider not only the pathological knowledge of diseases, but also its traditional concern of the well-being of patients, so that it could truly contribute to making human beings to live a good life.

However, can it really achieve the ideal of "patient-centeredness" in medical humanities alone by treating the patient as an autonomous subject? Or might it be a risk to oversee the real situation and experience of the patient? In other words, is it enough to appeal to the autonomy of the patient to treat the patient as a suffering person? 
This article aims to argue that patient autonomy is not the sufficient condition for patientcenteredness, and that care ethics is indispensable in the practice of medical humanities to actualize the doctor-patient relationship in humanistic care. Firstly, we will explain why the concept of patient autonomy alone cannot fulfil the ideal of patientcenteredness, and what its main problem is. Secondly, we will re-consider the doctor-patient relationship under the theory of care ethics and thus demonstrate that we can break away from domination of modern medical knowledge by falling back on care ethics for returning to the caring relation between doctor and patient in the real life-world. Thirdly, we will highlight the significance of trust and dependency in care ethics in order to avoid turning the caring for the patient to an oppressive requirement for the doctor, since both the doctor and the patient experience the fragility of human existence. Finally, we attempt to respond to the current clinical dilemma between cure and care on the basis of the understanding of humanistic spirit of doctor-patient relationship presented in care ethics.

\section{THE INSUFFICIENCY OF PATIENT AUTONOMY FOR PATIENT-CENTEREDNESS}

Patient autonomy seems to be regarded by most medical professionals as the core embodiment of humanistic patient-centered ideal. It is derived from an assumption which Western modern ethics of justice is based on, i.e.: the realization of justice depends on the respect for individual autonomy and the requirement of equal rights. Accordingly, contemporary medical ethics forms four prima facie principles for health care: respect for autonomy, benevolence, non-maleficence and justice. Among such principles, patient autonomy is the first important one in the doctor-patient relationship and means nothing but treating the patient as an independent, rational subject who can have full autonomy and participate in medical decisionmaking. [7] However, this principle eventually ignores the existential difference between patient and doctor as well as the real experience of the person in suffering. Thomasma argued that "the patient autonomy model ignores the impact of disease on personal integrity" [16], and pointed out that the physical changes of the patient caused by a disease manifest themselves not only in external symptoms, but also in the patient's internal reassessment of her/his own life. If a disease changes the personal wholeness of a patient radically, her/his individual autonomy will thereby be undermined correspondingly. [16] [7] This is because the patient doesn't necessarily have a sound mental capacity to make the best choice for her/his own well-being in this moment. In other words, although the mainstream opinion in medical humanities based on the ethics of justice and its principlism is meant to ensure the patient's right in the doctor-patient relationship, it still lacks an appropriate observation of the real, lively and personal encounter between doctor and patient.

We are not denying the principle of patient autonomy here, since it can give patients a right to participate in medical decision-making. We are merely criticizing the assumption of that principle which the mainstream opinion holds, i.e. the ethics of justice and its rational reasoning for every patient. According to it, every patient as a rational subject is an independent and self-sufficient self and any irreducible aspects of lived experience, feelings, emotions and personal relations shouldn't be included in the her/his decision and choice. Moreover, this kind of humanistic thinking not only regards patient autonomy as priority in health care, but also regards the doctor-patient relationship merely as a collection of plural subjects by making one's own self as flat as the others'.

Thomasma argues that the patient "has a certain 'completeness' that transcends rationality". [17] It is undoubted that a person completes her/himself through the interaction with the others in everyday life. But in the situation of patients, such a completeness - or wholeness - of life may cause them to make decisions which are hardly justified with reason. Although such a decision cannot be understood by abstract theoretical reasoning, we can still find out some ways to understand the meaning of that decision. For example, a caregiver of a patient can often do it very well, while she/he intuitively recognizes the integrity of the latter's life. Just as Schmid has pointed out, the medical treatment process is for doctors a response to others who are completely different from themselves. [12] Therefore, the ethical challenge for them is not merely to make a rational decision to resolve a moral dilemma on-site, but to give a respond to the enigma of life under the commonly recurrent fragility of human existences, otherwise this decision-making couldn't be really patient-centered. Since medical humanities try to reach patientcenteredness from the principle of patient autonomy, they will ignore variable and unique experiences of different patients during suffering and their reconstructing the meaning of their own 
life as a whole. In short, the real doctor-patient relationship will be reduced to a dry intersubjective relation with a clear distinction of responsibility for both sides.

The insufficiency of patient autonomy for patient-centeredness manifests itself especially in the patient's being at a loss to when the doctor gives her/him the full right to decide which medical treatment should be taken. It seems that the patient autonomy proposed by ethics of justice in order to solve the doctor's dilemma has in turn caused the patient's dilemma. In order to grasp the real dilemma of the patient and to find another approach to reaching the patient-centered doctor-patient relationship, we must go beyond the ethics of justice and its principlism. Care ethics seems for us to be a good candidate for this task.

\section{RESORT TO CARE ETHICS: AN ALTERNATIVE APPROACH TO PATIENT-CENTEREDNESS}

Care ethics originally comes from Carol Gilligan's challenge to Kohlberg's moral development theory. [4] According to her, Kohlberg's theory implies a male ethical viewpoint of justice and rights, which leads him to misunderstand and misappraise female ethical viewpoint and thus regard women's moral judgments as a failure at moral reasoning abstractly for universal justice. In contrast to the male viewpoint for the post-conventional era which is eager to conceive objective moral principles rationally, women's moral judgments often appear vague and uncertain because they insist on the relativity of moral situation. The understanding of morality by women is based on the responsibility for the whole world and the concern for the real lives of others, rather than on the priority of certain universal rights. The care for others and the awareness of responsibility is not at all a result of immature cognitive-development of moralization, as Kohlberg criticized, but a completely different dimension of moral thinking. Therefore, Gilligan appeals to the psychological study on the development of women's moralization to support her argument and puts forward an alternative ethical thinking different from the ethics of justice - i.e. ethics of care. [4]

Nel Noddings continues Gilligan's psychological description of the ethics of care. From the analysis of caring relations, she illustrates further the ethics of care as the philosophical basis of ethics. Noddings first describes the position of care ethics in contemporary moral viewpoints and posits it as a perspective far different from the ethics of justice. The core of care ethics is the pursuit of moral attitude and goodness rather than moral reasoning. In other words, care ethics does not regard moral relationships as governed by formal rules. Rather, in order to understand moral relationships appropriately, we should return to their situations in reality. Noddings argues that "care" should not be grasped as a personal emotional preference, but as an ontological connection between real people. Care is the correlation made up of the one who is caring and the another who is cared for. The one-caring and the cared-for are existential in the real world, and not two merely rational subjects in a theoretical world. Both of them are determined in a caring relation. For Noddings, the human relation here is not formed by plural selves, but "will be taken as ontologically basic and the caring relation as ethically basic". [8] In other words, human relation is prior to the self in the existence of human beings. From the perspective of ontology, the basis of ethics is the caring relation rather than the formal moral self. Thus, Noddings argues that it is the original "natural caring" between people that makes the "ethical caring" in moral practice possible. [8]

Noddings goes on to point out that "care" means a state of mental suffering including burden, anxiety, fear or solicitude about something, and also the regard for others whom we turn our existential attention from ourselves to. [8] Noddings further describes care as seeing "other's reality as a possibility for my own", namely as a kind of engrossment which is "aroused in me something" and not to project myself into others. [8] In other words, engrossment is not empathy, which is an intention to project our personalities into others. It is different from Kohlberg's idea of role taking which images oneself as others so as to know themselves. In caring, we are not replacing the selves of others with our own selves, but feeling others before any analysis begins. Therefore, we can regard the reality of the other as a possibility of our own. Only by engrossment can we further achieve motivational displacement and act out our concern for others. In this sense, the ability to care is not some kind of rational analysis or hypothesis but a dedication to the relationship. As a result, Noddings criticizes such an empathy theory led by the male-dominated ethics of justice because empathy is nothing but an epistemological technique which isn't based on the authentic ontological foundation of human beings. In 
empathy, one only attempts to understand others through external signs of their behaviours and to use her/his personal viewpoint to imagine the viewpoints of others, but eventually does not intend to let others to be present with her/himself. In contrast to it, engrossment is a state of being open to others and being moved by others. In engrossment, one does not interpret the needs of others with her/his needs, but dedicates her/his self to receiving - she/he needs to lay aside any personal preunderstandings to be touched by others. In addition, the ethics of justice tries to eliminate personal perspectives through the epistemological method of abstraction in order to reach universal moral principles, while it actually reinforces the male perspective in a disguised way. On the contrary, the female perspective of moral agent does not focus on reasoning or analysis of abstract intersubjectivity, but on the dedication to concrete human relationships. A last thing to be emphasized is that the caring consciousness in human relationships is eventually not a psychological trait unique to women, but a basic fact of human existence for everyone. It roots ontologically more deeply in human mind than the demand for the principle of justice. [7]

As mentioned above, patient autonomy is based on the assumption of the ethics of justice that a moral agent is an independent and self-sufficient self and any personal perspectives should be eliminated. In this sense, it is at the same time a disguised reinforcement of one perspective overriding the others. Radically speaking, this is even to treat others as objects rather than subjects, because it ultimately leads to a kind of domination over others in the name of moral obligation, instead of considering their personal needs. If we now are to take their needs seriously and treat them as subjects who share their lives with us, we must return to the real human relationship. Human relationship exists ontologically already prior to any single subjects and cannot be arbitrarily interpreted only by any single one in this relationship. Every moral agent's perspective should be seriously included and considered in an authentic relationship. The situation is same in the caring relation. In an authentic care, we let others' personal viewpoints encounter us and try to understand them as who they really are, so that we can respond to their personal needs rightly. Therefore, it seems that we can apply care ethics as an alternative approach to the doctor-patient relationship, so that the doctor can perceive the patient as a whole and respond to diverse reactions of the patient on the basis of her/his ability of natural care.

To think about the doctor-patient relationship from the perspective of care ethics is to regard the doctor as the one-caring and the patient as the cared-for. At first glance, care ethics seems to solve the problem of ignoring and oppressing the patient's personal needs in the ethics of justice and thereby to overcome the oppression there. However, there may still be an oppression in the doctor-patient relationship under care ethics, that is, it may simply reverse the unfair structure in the ethics of justice and transform the oppression of patient's needs into the oppression of doctor's need. In other words, it is still possible that such a demand for care can also form an excessive oppression and request of doctors, if it drains them out and makes them sacrifice themselves to satisfy whatever their patients want. If this were the result of applying care ethics, it will undoubtedly violate the core value of care ethics. Therefore, in the next section, we will further introduce Eva Kittay's concept of dependency relations and Annette Baier's theory of morality of trust to explore the connotation of care ethics, in order to reveal the doctor-patient relationship under care ethics more deeply.

\section{FURTHER DEVELOPMENT OF CARE ETHICS: DEPENDENCY, TRUST AND THE VULNERABLE WE}

Following Noddings' critique of the independent and self-sufficient moral subject assumed in the ethics of justice, Kittay and Baier develop their feminist theories by understanding human as a fundamentally relational and fragile being. For human beings, independency and self-sufficiency are eventually exceptional situations, while trust and dependency are more common situations in their everyday life. [21] As Kittay pointed out, dependency relationship is the basic situation in our life. When we were children, none of us could avoid the experience and relationship of direct relying on the others. Dependency always further derives dependency. Since dependency work will make it impossible for dependency workers to invest in certain activities of everyday life equally, so that they will inevitably become dependents in other aspects. [20] In other words, no matter who we are, we all become dependents in a certain way. What constitutes the nexus between dependents and those depended on is basically not a rational contract for both sides, but a mutual trust. 
According to Baier's ethics of trust, the trust relationship is different from the relationship constructed by contract, because it is not based on an equivalent exchange, but on a dependency managed by mutual emotions under a non-equal situation. [21] Therefore, the trust relationship is not formed by the voluntary and conscious decision of independent subjects, but exists already in the dependency relationship between those who face their own fragility and entrust it to each other.

In the caring relation, we can observe that the one-caring happens to be the only one, or one of a few, who can protect the cared-for from harm on site, so that the dependency relationship between them is often both non-voluntary and non-coerced. [20] This is the same in the doctor-patient relationship. Of course, it cannot be denied that doctors do establish a contractual relationship with patients because they charge a fee for treatment. If we only determine the nexus between doctors and patients in terms of voluntariness, we will simply ignore their need for dependency. From a deeper perspective, what doctors encounter is an alive face of suffering in front of them. And patients have a need to depend on doctors because of their fragility. At this moment, patients have a greater need to be treated by a trustworthy doctor, otherwise they may feel uneasy in entering the clinical relationship. However, besides the fragility of patients as dependents, doctors as dependency workers actually often become fragile while providing care services, whether voluntarily or not. In other words, not only patients but also doctors are vulnerable. When doctors are committed to satisfying the needs of patients, they place themselves in a vulnerable situation, so that they may not only give up participation in other public activities, but also neglect their own basic needs. They even do not always have the ability to rescue all the sufferers in front of them, nor are they always in a good condition to devote themselves to care services. As a result, they may feel exhausted. As Kittay pointed out, such a situation will finally cause the poverty of dependency workers. [20] Therefore, even doctors need to resort to trust when entering a clinical relationship, i.e. trusting patients to understand their personal needs, and not to impose unreasonable demands on them.

From the previous analysis on dependency and trust, the theory of care ethics has gained a further step of deepening. According to care ethics, the basic of doctor-patient relationship is not the contract of rights between two rational subjects, but the caring relation between the one-caring and the cared-about. This first concludes that people in a relationship cannot be reduced to abstract autonomous individuals. Then it highlights the common experience of human fragility and dependency in the doctor-patient relationship, and thus the need for trust in each other. Once we can face the common vulnerability of both sides, we can find that the ideal of patient-centeredness in medical humanities based on ethics of justice is indeed easy to cause excessive oppression of doctors in the doctor-patient relationship, namely, requiring doctors to sacrifice themselves endlessly without considering their own needs at all. However, merely to reveal the fact of common vulnerability is not enough to completely solve the oppressive structure in the doctor-patient relationship. Care ethics still needs to find a proper way of interaction for fragile doctors and patients in order to establish a non-oppressive doctor-patient relationship. Therefore, we will appropriate Peter F. Schmid's concept of "dialogic position of the 'We'" and propose a possible doctor-patient relationship of care ethics constituted by a therapeutic dialogue.

Schmid tried to expound the mutual understanding in the doctor-patient relationship from the approach of person-centered psychotherapy, and argued that it is the "We" as an existential fundamental form which makes this mutual understanding possible. [11][12] In showing how individuals form relationships - or how the "I"s become the "We" - , Schmid pointed out that the "I" is already in a relationship of the "We" when it encounters the "other". And there are four patterns of the "We" as follows: (1) individualistic position $([\mathrm{I}]+[\mathrm{I}]=\mathrm{We})$, which regards the "We" as a stock of isolated egos, represented by [I], and gives priority to individuality so that it is difficult to reach a real We-relationship; (2) collectivistic position $(\mathrm{We}=[\mathrm{I}]+[\mathrm{I}])$, which cancels the individuality of isolated egos and gives priority to totality by reducing every ego into the "We"; (3) humanistic position ( $\mathrm{We}=\mathrm{I}+\mathrm{you}$ ), which regards the alter ego under the We-relationship as a "you" which is different from the "I" and cannot be reduced to the "I", while it can be known analogically from the viewpoint of the "I"; (4) personal or dialogic position $(\mathrm{We}=\mathrm{you}+\mathrm{I})$, which starts epistemologically from an unknown "you" and regards the formation of the "I" as a derivation from recognizing the otherness of the "you", so that the viewpoint of the "I" under the We-relationship is developed from its being from the viewpoint of the "you". [11] 
According to Schmid, the dialogic position of the "We" describes the real We-relationship and is the basis of person-centered psychotherapy. [11] It is shown in the dialogic position that the Werelationship in nature is not symmetrical, but asymmetrical. It is this asymmetry that brings out the deep meaning of a "subject" ontologically, i.e. "subject" does not primarily act as a rational and autonomous self in a solipsistic universe, but act as a "sub-ject" to belong to the other. To be a person is not to be a being-for-me, but a being-for-the-other. [11] Therefore, we are not just situated in a relationship; we are rather the relationship itself. [11] In this sense, "Subjectivity" is in itself relational, and not the "I for myself". [12]

As Levinas reminded, on the one hand, human beings are a bodily existence and thus so vulnerable that they need the care of the other to survive. On the other hand, human beings share with each other the difference and otherness which originated from their particular situation within the world. [1] Following Levinas' insights, Kottow points out that the clinical encounter is essentially a moment of ethical encounter where one is face-to-face with the other. [5] When the other shows me a suffering face which indicates the need for help or protection, I become a "subject" due to the recognition of her/his calling and the responsibility to her/him. The Levinasian observations correspond precisely to the analysis of care ethics. Now if we combine those together with the We-relationship in Schmid's dialogic position and put all these back into the context of doctor-patient relationship, we will be able to have a more complete picture of the doctorpatient relationship in care ethics. In this picture, both the doctor and the patient will be aware of their common fragility and can understand not only the patient's different situation, but also the doctor's unique position because of the asymmetric structure of the We-relationship. Therefore, both parties can avoid the oppression caused by one-sided appeal to patient-centeredness or doctor-centeredness. Following Schmid's person-centered perspective, the doctor-patient relationship of care ethics is a We-relationship where everyone communicates and understands with each other face-to-face and can really meet the other in the caring relation.

\section{CONCLUSION}

Under the trend of medical humanities, Taiwan officially implemented the "Patient Right to Autonomy Act" in 2019. The first article of this act states that "this Act is stipulated to respect patient autonomy in healthcare, to safeguard their rights to a good death, and to promote a harmonious doctorpatient-relationship." Unfortunately, it doesn't profoundly define the autonomy of the patient. "Autonomy" means simply that every decision is made by oneself voluntarily without any external restriction. The theoretical origin of this kind of autonomy can be traced back to Plato's philosophical account, which determines human beings as composition of two opposing parts: the passive, dependent part of desire and the active, self-sufficient part of reason. Plato believes that only in the latter part, we are the truly agent of ethical action. But Nussbaum criticizes such a Platonic assertion and tries to return to Aristotle's account for a moral life. She pointed out that human existence oscillates between these two parts, and these two parts actually are not opposite to each other, but inseparable with each other. Nussbaum argues that traditional moral philosophy (such as utilitarianism and Kantian deontology) only considers the relation between rational action and ethical responsibility, and discusses ethical action in the category of rationality, so that it has long ignored the "insufficiency" and "vulnerability" in human nature; on the contrary, she believes that we can really take on our own existence and act morally only when we recognize the fundamental vulnerability of human beings. [9]

In short, the break of self-sufficiency is rather the real ethical scene which we must face directly. Only when we truly understand our own fragility and finiteness, we can achieve the true ethical practice and begin to experience our authentic existence. So said Nussbaum: "To all this a natural response is that this is not how it feels to be in that situation. It does not feel like solving a puzzle, where all that is needed is to find the right answer. If the idea of solving or ending the problem occurs, it is not as the hope of discovery, but as the idea of some more radical break: denial, deliberate callousness, even madness or death." [9] This does not mean that we cannot be autonomous, but that autonomy needs to be won once again in repeated common struggles.

Medical humanities are not only a response to the patient, but also aimed at responding to the ethical inquiry of "being a human". Because of this, we urgently need to point out an important aspect that medical humanities have so far ignored. Although doctors have more professional resources, abilities, and knowledge compared to the patient, they also share with them the common vulnerability and finiteness. Being a human does not mean to be 
an independent self-sufficient individual, but a "subject" in dependency and caring for others. Medical humanities expect doctors to have a complete understanding (sophia) about disease, pain, personality, or other related issues, to deepen their judgments (phronesis) in changing uncertain clinical scenes, and thereby to improving their treatment of the disease (praxis). [13] Following Nussbaum, we put forward "the fragility of goodness" as a necessary condition for the doctorpatient relationship. Human beings pursue goodness by nature, but their praxis of goodness is limited by opportunity (tuché) and even accompanied by pain in many cases because they are a finite existence. [19] Only when the vulnerability and fragility of the doctor is also comprehended, can we truly see how doctors and patients become partners of mutual caring in the world, although they are situated in an asymmetrical structure.

\section{AUTHORS' CONTRIBUTIONS}

Huei-Ya Chen wrote the manuscript, and WeiDing Tsai contributed to revising and editing.

\section{REFERENCES}

[1] Benner, P. (2001). The Phenomenon of Care. In S. K. Toombs (Ed.), Handbook of Phenomenology and Medicine (pp. 351-369). Dordrecht, NL: Kluwer Academic.

[2] Chiapperino, L., \& Boniolo, G. (2014). Rethinking Medical Humanities. Journal of Medical Humanities, 35(4), 377-387.

[3] Evans, H. M., \& Greaves, D. A. (2010). Ten Years of Medical Humanities: A Decade in the Life of Journal and a Discipline. Medical Humanities, 36(2), 66-68.

[4] Gilligan, C. (1982). In a Different Voice: Psychological Theory and Women's Development. Harvard University Press.

[5] Kottow, A. R., \& Kottow, M. H. (2007). The Disease-Subject as a Subject of Literature. Philosophy, Ethics, and Humanities in Medicine, $2(1), \quad 10$. https://doi.org/10.1186/1747-5341-2-10

[6] Kottow, M. H. (2001). Between Caring and Curing. Nursing Philosophy, 2(1), 53-61. https://doi.org/10.1046/j.1466769x.2001.00031.x

[7] Lin, Yuan-Tse. (2015). Care Ethics and Dialogical Cure: Philosophical Interrogation of Medical Humanities. Taipei: Wu-Nan Book Inc.

[8] Noddings, Nel. (1984). Caring: A Feminine Approach to Ethics and Moral Education. Berkeley: University of California Press. doi:10.1017/CBO9780511817915

[9] Nussbaum, Martha C. (2001). The Fragility of Goodness: Luck and Ethics in Greek Tragedy and Philosophy (2nd ed.), Cambridge: Cambridge University Press.

[10] Price, L. (1984). Art, Science, Faith and Medicine: The Implications of The Placebo Effect. Sociology of Health \& Illness, 6: 61-73. https://doi.org/10.1111/14679566.ep10777362

[11] Schmid, P. F. (2003). The Characteristics of a Person-centered Approach to Therapy and Counseling: Criteria for Identity and Coherence. Person-Centered and Experiential Psychotherapies 2(2), 104-120. doi:10.1080/14779757.2003.9688301

[12] Schmid, P. F. (2006). The Challenge of the Other. Towards Dialogical Person-centered Psychotherapy and Counseling, in: PersonCentered and Experiential Psychotherapies 5:4, 241-254. doi: $10.1080 / 14779757.2006 .9688416$

[13] Shapiro, J., Coulehan, J., Wear, D., \& Montello, M. (2009). Medical Humanities and Their Discontents: Definitions, Critiques, and Implications. Academic Medicine, 84(2), 192198.

[14] Svenaeus, F. (2001). The Phenomenology of Health and Illness. In S. K. Toombs (ed.), Handbook of Phenomenology and Medicine (pp.87-108). Dordrecht: Kluwer Academic Publishes.

[15] Svenaeus, F. (2011). Illness as Unhomelike Being-in-the-world: Heidegger and the Phenomenology of Medicine. Medicine, Health Care and Philosophy, 14(3), 333-343.

[16] Thomasma, D. C. (1983). Beyond Medical Paternalism and Patient Autonomy: A Model of Physician Conscience for the PhysicianPatient Relationship. Annals of Internal Medicine, 98(2), 243-248.

[17] Thomasma, D. C. (1994). Clinical Ethics as Medical Hermeneutics. Theoretical Medicine, 15(2), 93-111.

[18] Toombs S. K. (2001). Reflections on Bodily Change: The Lived Experience of Disability. 
In S. K. Toombs (Ed.), Handbook of Phenomenology and Medicine (pp. 247-262). Dordrecht, The Netherlands: Kluwer Academic Publishers.

[19] Wang, Wen-Sheng. (2019). Phenomenology as a Practical Philosophy: Husserl, Heidegger and Arendt's Ethics, Politics and Philosophy of Religion. Taipei: Linking Publishing.

[20] Wu, Shiu-Ching. (2005). Dependency and Equality: On Kittay's Love's Labor. Journal of Women's and Gender Studies, 19,157-184.

[21] Wu, Shiu-Ching. (2006). Moral Implications of Care Ethics: A Study of Feminist Transformations of Moral Practices. NCCU Philosophical Journal, 16,107-116. 